\title{
Narrativa, Hipertexto e as Categorias da Enunciação: aproximações na composi- ção de um conceito de narrativa hiper-
}

textual

\section{Marcelo Freire *}

Resumo: Este artigo faz uma revisão de literatura utilizando as categorias de enunciação para a observação de narrativas hipertextuais. Para tanto, aproximamos autores do campo dos estudos de linguagem, como Maingeuneau, Charedeau, Fiorin e Eco, e outro ligados às novas tecnologias, como Manovich, Liestøl, Palacios e Mielnizuk. Assim buscamos conjugar abordagens diferenciadas à análise da função do link na composição de histórias.

Palavras Chave: narrativa hipertextual, categorias da enunciação

Resumen: Este artículo hace una revisión bibliográfica utilizando las categorías de enunciación para la observación de las narrativas hipertextuales. Para eso, nos acercamos de autores del campo de los estudios de lenguaje, como Maingeuneau, Charedeau, Fiorin y Eco, y por otro lado de autores de tecnologías, como Manovich, Liestøl, Palacios y Mielnizuk. De esa manera, nuestro objetivo es conjugar abordajes distintas al análisis de la función del link en la composición de historias. Palabras Clave: narrativa hipertextual, categorías de enunciación

Abstract: This article propose a literature review using the categories of enunciation for the observation of hypertext narrative. For this, we bring together authors of the language studies, as Maingeuneau, Charedeau, Fiorin and Echo, and other related technologies such as Manovich, Liestøl, Palacios and Mielnizuk. So we try to combine different approaches to analyzing the function of the link in the composition of stories.

Keywords: hypertext narrative, categories of enunciation

\section{Introdução}

Este artigo pretende, através de uma revisão de literatura, aproximar dois campos dos estudos de linguagem, a narrativa clássica e as categorias de enunciação, para a busca de um conceito de narrativa 
hipertextual, focado nas embreagens e debreagens como elemento de vinculação entre blocos de texto em rede. Esta relação entre a narrativa e as redes telemáticas é um tanto recente. Michael Joyce $(\mathrm{s} / \mathrm{d})$ destaca que a narratividade hipertextual é ainda uma adolescente. Portanto, a busca por uma sistematização ou uma formatação para ela é um desafio para diversos autores. As mudanças não são apenas nas ferramentas ou suportes e, sim, na forma de pensar a maioria dos elementos da narrativa tradicional.

Hipertexto é, claro, jovem em qualquer medida - 47 anos desde o Memex de Vannevar Bush, 29 desde a ampliação de Engelbart, 27 desde o hipertexto de Nelson e cinco anos desde que nos reunimos em grande número no primeiro encontro da ACM sobre hipertexto em 1987. A narrativa é antiga [...] isso porque o hipertexto pensa em si próprio mais como sendo estrutural do que um pensamento seriado - pensamento no espaço mais do que pensamento por um espaço (JOYCE, s/d). ${ }^{2}$

O autor ressalta que as mudanças não incluem apenas novos elementos à narrativa tradicional, mas mudam o seu ferramental. Elas a redefinem e a refinam. Por isso, para tentar entender as diferenças entre essas duas formas de contar histórias vamos buscar os elementos básicos da narrativa clássica, como eles se relacionam com jornalismo e, mais especificamente, com a reportagem. Depois analisaremos as alterações trazidas pelas novas tecnologias e buscaremos um conceito de narratividade hipertextual que deve guiar as análises. Isso vai nos dar elementos para entender e identificar estratégias discursivas adotadas através das formas de contar histórias.

\section{Narrtiva e narratividade}

Inicialmente, vamos trazer o conceito de narrativa para entender quais são os elementos que compõem uma história e seu processo de elaboração. Para Osvaldo Coimbra (1993) narrar é contar um acontecimento com uma relação de anterioridade e posterioridade. Luis Gonzaga Motta (2005) a define de forma ainda mais abrangente:

A narrativa traduz o conhecimento objetivo e subjetivo do mundo (o conhecimento sobre a natureza física, as relações 
humanas, as identidades, as crenças, valores e mitos, etc.) em relatos. A partir dos enunciados narrativos somos capazes de colocar as coisas em relação umas com as outras em uma ordem e perspectiva, em um desenrolar lógico e cronológico. É assim que compreendemos a maioria das coisas do mundo (MOTTA, 2005, p. 2).

Esta definição aborda o resultado do processo de formação de sentido e destaca a sua importância para compreendermos o "objetivo e subjetivo do mundo", entretanto, deixa claro que a narrativa é o resultado de relatos. O semioticista Umberto Eco atribui à narrativa uma função consoladora e acredita que por essa razão as pessoas contam histórias desde o início dos tempos. "Sempre foi a função suprema do mito: encontrar uma forma no tumulto da experiência humana” (ECO, 1994, p.93). Já Lev Manovich faz uso da obra do narratólogo Mieke Bal para buscar uma perspectiva mais pragmática do que compõe uma narrativa: "ela deveria conter ambos, um ator e um narrador; deveria também ter três diferentes níveis que consistem no texto, na história e na fábula; e esse conteúdo deveria ser "uma série de eventos conectados causados ou experimentados pelos atores"3 (MANOVICH, 2001, p. 201). Manovich faz uma importante distinção entre narração e descrição. A primeira é a que faz o enredo "andar" e a segunda é quando isso não acontece. Para Fiorin, "a narrativa é um simulacro das ações humanas e uma Teoria Narrativa é, antes de mais nada, uma Teoria de Ação” (2002, p. 32). Para abordar essa ação em curso e seu resultado concluído, trabalharemos com duas idéias: narrativa e narratividade, respectivamente, produto final e seu processo de formação de sentido.

Chamaremos de narratividade a tudo o que se apresenta ante a concatenações e transformações de ações e paixões . [....] A narratividade é, radicalmente, um ato de configuração do sentido variável de ações e paixões; ações e paixões que podem estar organizadas do ponto de vista da forma do seu conteúdo, ou seja, de sua semântica, e podem ser manifestadas por uma forma de expressão distinta (verbal, gestual, musica etc.) (FABBRI, 2000, p. 57-58). ${ }^{4}$

Para nós, a compreensão deste processo é fundamental para determinarmos ou, ao menos, delimitarmos como ele se configura nas redes telemáticas. Consideramos a denominação de Fabbri adequada 
por incluir elementos verbais, gestuais e musicais na formação do processo narrativo. Isso porque Fabbri não avalia a narratividade como um produto fechado, e sim como um processo. Como estamos trabalhando com a idéia de narratividade, estamos tratando, na verdade, de processos enunciativos. José Luiz Fiorin, parafraseando Edgard Morin, destaca duas teses centrais para esses processos: "(a) o discurso, embora obedeça as coerções da estrutura, é da ordem do acontecimento, isto é, da História e (b) Não há acontecimento fora dos quadros do tempo, do espaço e da pessoa" (FIORIN, 2002, p. 14). O autor defende que a compreensão dos mecanismos de temporalização, de espacialização e de actorialização é fundamental no processo de discursivização. Para Maingueneau, o discurso "se desenvolve no tempo, de maneira linear. $\mathrm{O}$ discurso se constrói, com efeito, em função de uma finalidade, devendo, supostamente, dirigir-se para algum lugar" (2005, p. 53). Ao longo deste artigo, apresentamos as três categorias da enunciação, tempo, espaço e pessoa e desenvolvemos uma abordagem a partir da correlação destas dimensões com as aproximações de Gunnar Liestøl da perspectiva de Gérard Genette sobre a questão do tempo, a idéia de Lev Manovich de espaço navegável e de multivocalidade de Bakthin.

\section{O enunciador e as categorias da enunciação}

Antes de estabelecermos essas relações é preciso fazer algumas considerações em relação ao link. Consideramo-lo como elemento estruturante do hipertexto responsável pela ligação entre dois nós (cf. LEVY, 1995) e com uma importante função paratextual (cf. MIELNICZUK e PALACIOS, 2001), mas não pretendemos aqui fazer mais uma tipologia ou um estudo de "linkologia". A proposta que fazemos é de considerar, na composição de uma narrativa hipertextual, o link como o responsável pelo movimento de embreagem e debreagem que instaura as categorias da enunciação. A importância desta proposição se dá, acreditamos, por estipular uma ferramenta de identificação de links de forma independente da sua função, seja complementação, contextualização etc., e sim dos elementos discursivos mais elementares.

$\mathrm{Na}$ enunciação, o enunciador utiliza mecanismos chamados: debreagem e embreagem. No hipertexto, expandimos a ação desse mecanismo, colocando-o como elo entre duas lexias. 
Os mecanismos de instauração de pessoas, espaços e tempos no enunciado são dois: a debreagem e a embreagem. Debreagem é a operação em que a instância de enunciação disjunge de si e projeta para fora de si, no momento da discursivização, certos termos ligados a sua estrutura da base, com vistas a elementos fundadores do enunciado, isto é, pessoa, espaço e tempo (Greimas e Courtès, 1979, p.79). [...] A debreagem consiste, pois, num primeiro momento, em disjungir do sujeito, do espaço e do tempo da enunciação e em projetar um não-eu, não-aqui e um não-agora. Como nenhum eu, aqui e agora inscritos no enunciado são realmente a pessoa, o espaço e o tempo da enunciação, uma vez que estes são sempre pressupostos, a projeção da pessoa, do espaço e do tempo da enunciação no enunciado é também uma debreagem (Greimas e Courtès, 1979 p.79). [...] Ao contrário da debreagem que expulsa da instância de enunciação a pessoa, o espaço e o tempo do enunciado, a embreagem é "o efeito de retorno à enunciação”, produzido pela neutralização das categorias de pessoa e/ou espaço e/ou tempo, assim como pela denegação da instância do enunciado. [grifos do autor] (FIORIN, 2002, pp. 43-47).

Sempre que o enunciador dá voz de fala a uma personagem acontece a embreagem e quando retoma a narração ocorre uma debreagem. Seguindo a mesma lógica em relação às demais dimensões do discurso, podemos afirmar que quando ele se remete a um tempo diferente da narração ou evoca um espaço diferente do que ele narra acontece a embreagem. As debreagens são os movimentos inversos. Por exemplo, sempre que o enunciador faz um flashback, ele se refere a um tempo diferente do agora da enunciação. Isso representa uma debreagem de tempo. Quando ele retoma o tempo da narração temos o movimento inverso, uma embreagem. $\mathrm{O}$ mesmo acontece em relação ao espaço quando se descreve um local diferente ao que está o enunciador, acontece uma debreagem de espaço. Em relação à pessoa, esses movimentos se estabelecem quando a fala é cedida a outro personagem que não o enunciador. No caso do jornalismo, poderíamos exemplificar com seções e retomadas de fala em uma entrevista.

Outro estudioso, Dominique Maingueneau (2005), trata dos conceitos de embreagem e de não-embreagem. Para ele, "chama-se de embreagem o conjunto de operações pelas quais um enunciado se ancora na sua situação de enunciação" [grifos do autor] (2005, p. 108). De 
acordo com o lingüista (2005, p.113-114) fala-se em enunciado embreado, geralmente quando esse contém, além de embreantes, outras marcas da presença do enunciador: apreciações, interjeições, ordens, interpelação do co-enunciador. "Os enunciados "embreados" constituem a imensa maioria dos enunciados produzidos. É difícil imaginar o que seria uma conversa que não remetesse ao contexto da enunciação ou que não interpretasse o co-enunciador" (MAINGUENEAU, 2005, p. 114). Já quando essas marcas não estão presentes, o autor categoriza-o como não embreado.

Pode-se igualmente produzir um enunciado desprovido de embreantes isolado da situação de enunciação: fala-se então de enunciado não embreado. Os enunciados não embreados não são interpretativos em relação à situação de enunciação; eles procuram constituir universos autônomos [grifos do autor] (MAINGUENEAU, 2005, p. 114).

Essas marcas podem ser aplicadas, ou não, em qualquer uma das categorias da enunciação e, se aplicadas, criam uma relação direta entre dois blocos de texto, seja de aproximação ou distanciamento dos atores, ações ou espaços. Podemos pensar na associação entre um fato contado por dois narradores. Há uma cessão da fala por parte do enunciador e, portanto, uma embreagem de pessoa. Outro exemplo seria um avanço ou retomada em relação ao tempo da narrativa, que poderia ser interpretado como embreagem de tempo ou o mesmo em relação ao espaço. Esse tipo de associação define que dois blocos fazem parte da mesma narrativa, têm uma relação textual. Essa necessidade de buscar um mecanismo discursivo que una duas lexias no hipertexto é cada vez maior devido ao maior volume do uso de base de dados como ambiente, principalmente quando se trata de narrativas jornalísticas. Vicente Gosciola aponta a hipermídia ${ }^{6}$ como "um processo comunicacional que depende do relacionamento entre seus diversos conteúdos e seu usuário. A hipermídia que não está em uso por alguma pessoa ou grupo delas é apenas um banco de dados, um repositório de conteúdos” (2008, p. 21). O pesquisador Elias Machado defende a hipótese que "o jornalismo digital em Base de Dados, como uma forma cultural típica da sociedade de redes, assume ao menos três funções: 1) de formato para estruturação da informação, 2) de suporte para modelos de narrativa multimídia e 3) de memória dos conteúdos publicados” (2005, p. 303). Para Lev Manovich, 
A narrativa é construída através da linkagem de elementos de uma base da dados em uma ordem particular, isto é, traçando uma trajetória que leva de uma elemento a outro. No nível material, a narrativa é só um conjunto de links, os elementos, por si só, permanecem guardados em uma base de dados. [...] Uma narrativa interativa (que pode ser chamada de "hipernarrativa" em analogia ao hipertexto) pode ser entendida como a soma de múltiplas trajetórias através de uma base de dados. A narrativa linear tradicional é uma entre várias outras trajetórias, isto é, uma escolha particular feita em uma hipernarrativa $^{7}$ (MANOVICH, 2001, pp. 200-201).

Para ele, a base de dados suporta a narrativa, mas uma seqüência arbitrária de dados não forma uma narrativa. Ele defende que o prérequisito é conter uma série de eventos causados ou experimentados por autores e consideramos que utilizando a embreagem e debreagem como critério temos sempre essa relação em uma das dimensões do discurso, ou seja, tempo, pessoa ou espaço.

\section{Categoria Tempo ou Da Narrativa Aristotélica ao Hiper- texto}

Começamos a observar a questão do tempo porque ela é a chave da organização dos elementos da narrativa aristotélica, primeira sistematização cronológica da forma de contar uma história. A cronologia da narrativa tradicional segue o percurso: apresentação ou introdução; complicação ou peripécia, ação que contrapõe os personagens ou altera a sua estabilidade; clímax ou nó e o desfecho ou desenlace, que retoma nova situação de equilíbrio após o conflito inicial (cf. ARISTÓTELES, s/d). Motta (2005) propõe a aproximação das narrativas midiáticas aos parâmetros principais da narrativa aristotélica, ou seja, histórias com princípio, meio e fim (introdução, desenvolvimento e conclusão), centrada nas ações dos personagens. Marcos Palácios (2005) se apóia no teórico de cinema Christian Metz para sistematizar a relação entre a narrativa e a sua organização temporal.

A narrativa é (...) uma seqüência duplamente temporal (...): Há o tempo da coisa contada e o tempo da narrativa (o tem- 
po do significado e o tempo do significante). Essa dualidade não só torna possíveis todas as distorções temporais que são lugar comum nas narrativas (três anos da vida do herói sintetizados em uma ou duas sentenças numa novela ou algumas cenas num filme, etc) (...) o que nos leva a pensar que uma das funções da narrativa é inventar um esquema temporal em termos de um outro esquema temporal (METZ apud PALACIOS, 2005, p.4).

Essa relação entre as duas linhas de tempo da história e do discurso é fundamental para as categorias criadas por Genette para analisar a narrativa e apropriadas por Liestøl para estudá-las no ciberespaço. De acordo com o pesquisador, "nas teorias da narrativa a distinção entre a história contada e o contar a história aparecem em numerosas constelações e contextos" (LIESTØL, 1997, p. 115).

\section{Figura 01 - Esquema de relação entre linhas de tempo}

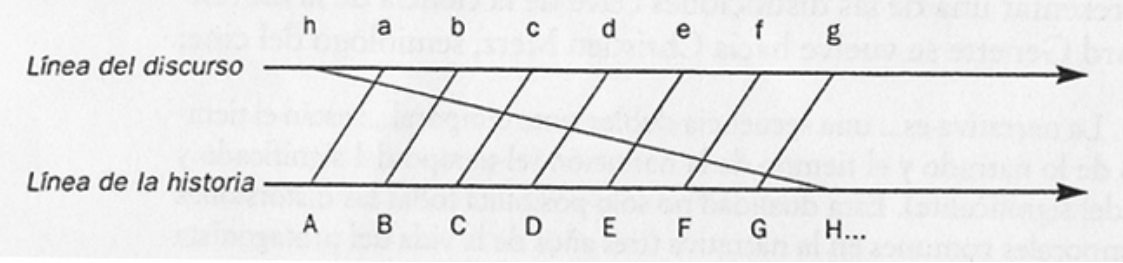

Fonte: LIESTØL, 1997, p. 115

Liestøl considera que a relação entre as duas linhas do discurso e da história, sobre a duração dos acontecimentos, pode se dar de cinco formas, como: resumo, elipse, cena, alargamento ou pausa ${ }^{9}$. O autor explica a elipse como os intervalos no tempo da história quando é preciso fazer uma retomada no tempo do discurso e que ela é um elemento necessário para o resumo. $\mathrm{Na}$ cena, o tempo do discurso e da narrativa são idênticos. No alargamento, a linha do discurso é maior do que a da narrativa e na pausa não há alteração na linha da narrativa. Segundo ele, "nos hipermeios, a interatividade permite ao usuário escolher a velocidade, quantidade e qualidade da informação ${ }^{10 "}$ (1997, p. 117). Com essa possibilidade podemos considerar que o leitor pode comprimir ou descomprimir a narrativa hipertextual optando por nós que tratem de 
trechos maiores ou menores de história. Resumos ou elipses, no caso de contextualizações históricas ou retomada de fatos anteriores; Alargamento, em um detalhamento de um momento da narrativa, como os detalhes de um acidente ou a cena em um flagrante de um vídeo amador ou qualquer transmissão em tempo real. Contudo, é na pausa, apontada por Liestøl como difícil de representar e que poderia equivaler a uma imagem estática ou algo do gênero, que podemos fazer a correlação com Manovich e Bakthin.

\section{Figura 02 - Relação entre linhas do discurso e da história}

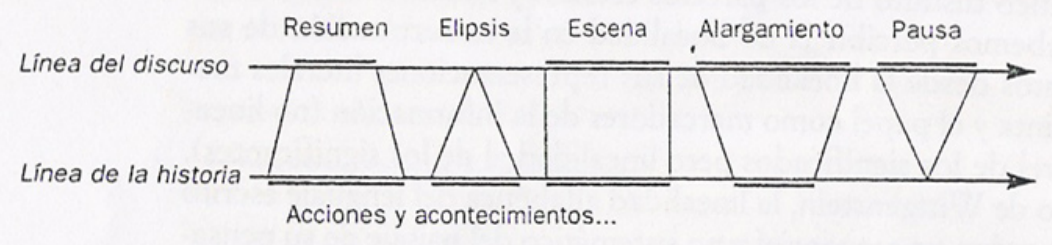

Fonte: LIESTØL, 1997, p.115.

Retomando a definição de Lev Manovich de que a diferença primordial entre narrativa e descrição é que uma "move" o enredo e a outra não, podemos considerar uma pausa como o espaço da descrição na relação entre as linhas do discurso e da história. Para o autor, nas novas mídias temos que reavaliar essas diferenças.

Ao invés de narração e descrição, seria melhor nos pensarmos em jogos em termos de ações narrativas e exploratórias. Melhor do que ter sido narrado, o próprio jogador tem que realizar suas ações para que a narrativa siga em frente: falando com outros personagens que ela encontra no mundo do jogo, recolhendo objetos, lutando com inimigos e assim por diante. Se o jogador não faz nada, a narrativa para. Com essa perspectiva, movimentar-se pelo mundo do jogo é uma das principais ações narrativas ${ }^{11}$ (MANOVICH, 2001, p. 215).

Ou seja, podemos pensar no estabelecimento de uma narrativa mesmo quando não há ação entre os atores, mas somente a exploração do espaço navegável. As categorias de Liestøl, salvo a pausa, têm uma 
relação direta com a quantidade de ação contida em uma lexia e essa é a vinculação que podemos fazer com o movimento de embreagem quando há um aumento, como no alongamento ou de debreagem quando há uma diminuição, no resumo e na elipse. Quando entramos na pausa, onde há a parada da narrativa e não do discurso, entramos no conceito manovichiano de descrição e de espaço navegável. A movimentação agora se dá na dimensão do espaço, onde a ação é controlada pelo leitor.

Neste espaço interativo, em que as ações estão articuladas às intervenções do explorador que incursiona pelo espaço navegável, fica evidente a necessidade de rever alguns postulados clássicos da narratologia como o de que a descrição interrompe a narrativa (Bal:130), muito apropriados para os modelos dos mitos, dos contos, dos romances policiais e do cinema de Hollywood, mas pouco adequados para interpretar as especificidades de formas narrativas descentralizadas das ações dos personagens, como as desenvolvidas no ciberespaço (MACHADO, 2007, pp. 104-105).

Então podemos considerar a ação do usuário (user-action), na categorização de Nora Paul e Christina Fiebich (2005), diferente da ação do conteúdo (content action). Quando essa ação de exploração se dá em relação ao cenário da ação podemos considerar as debreagens ou embreagens como aproximações ou afastamentos em um cenário digital ou descrição do mesmo. Essa dimensão do discurso é fundamental para referenciar as ações não apenas espacialmente, mas dentro de um contexto social. Suas relações com o narrador seguem a mesma lógica referencial da categoria tempo. Contudo, as relações que podemos apontar a partir dos marcos espaciais propostos na enunciação são de interioridade vs exterioridade, fechamento vs abertura e fixidez vs mobilidade. "O aqui é o fundamento das oposições espaciais da língua. Esse aqui, que se desloca ao longo do discurso, permanecendo sempre aqui, constitui os espaços do não-aqui" [grifos do autor] (FIORIN, 2002, p. 263). Essa referência, além de situar e descrever o aqui, o ambiente onde se desenvolve a ação, contextualiza o não-aqui, as noções de distância e o uso de expressões como perto, longe, atrás, à direita, etc.

\section{Contexto social como embreagem de espaço}


Outra abordagem do espaço sai da esfera apenas da enunciação e diz respeito à questão social, como se dão as relações sociais no cenário em que a narrativa acontece. Para tratar desta idéia temos que, inicialmente, abordar o conceito de glocal, um "neologismo resultante da bibridação cumulativa de dois termos, global e local" (TRIVINHO, 2004, p. 4). Para o autor, global e local são um e mesmo e, simultaneamente, nenhum; globalização (ou globalismo) e localização (ou localismo) restam dissolvidos.

A obliteração mediática do espaço territorial (tal como legado pela tradição e experienciado pelo senso comum), encadeada, no último quartel do século XIX, pela rede de telefonia, aprofundada, nas primeiras décadas do século $\mathrm{XX}$, pelo rádio e levada às últimas conseqüências pela televisão após a Segunda Guerra Mundial, produz, na cibercultura, por cumulação à reverberação dessas redes, socioespacializações audiovisuais específicas [...] Do território geográfico à interface e deste ao glocal: o percurso tecnológico avançado de obliteração do espaço realiza-se, com efeito, em consonância simultânea à reorganização do próprio lugar de inserção da existência: a glocalização cibercultural renova o contexto de acesso/recepção/retransmissão ao configurá-lo como reduto de livre confinamento interativo do corpo, da subjetividade e do campo próprio, locus a partir do qual se estabelece a relação com o mundo [grifos do autor] (TRIVINHO, 2004, pp.13-14).

A obliteração do espaço territorial em relação ao ciberespaço nos dá a clara idéia de que há uma possibilidade de compartilhamento global de produções simbólicas e imagéticas. Contudo, as representações sociais e visões de mundo específicas produzem o que o autor chama de bunker glocal. Para Trivinho, "o bunker glocal é um ethos específico, no sentido etimológico: forma de estar e de agir no mundo, em compatibilidade com as necessidades de reprodução social-histórica" [grifos do autor] (2004, p. 21). Isso cria uma representação local de uma realidade global. Desta forma, temos, em termos práticos, um contexto comparativo de modos de ver diferenciados a partir da repercussão local de assuntos compartilhados globalmente. Assim, se estabelece a relação entre o espaço social do enunciador, aqui, e o espaço social do co-enunciador, não-aqui. Essa relação de disparidade acontece quando ambos não compartilham as mesmas visões de mundo e características regionais. 


\section{Categoria Pessoa ou Multivocalidade e a Narrativa}

Outra possibilidade de navegação sem o avanço da narrativa é quando esse tipo de aprofundamento se dá em relação aos atores. Desta forma, podemos descrever os personagens sem envolver ações da trama ou buscar diferentes versões dos fatos a partir da inserção de outras vozes no discurso além da do narrador. Assim, temos uma aproximação do conceito de multivocalidade de Bakthin com embreagens e debreagens na dimensão pessoa feitas a partir das instaurações dos discursos direto, indireto e indireto livre. A multivocalidade, para Mielniczuk, não está apenas ligada à existência de muitas vozes, mas também em conteúdos de autoria coletiva.

A idéia de multivocalidade está relacionada ao conceito de polifonia de Bakthin: a possibilidade da existência de diversas vozes na narrativa literária. A fragmentação do texto em lexias favoreceria a multivocalidade, pois como explica Landow, "el hipertexto no permite una única voz tiránica. Más bien, la voz siempre es la que emana de la experiencia combinada del enfoque del momento, de la lexia que uno está leyendo y de la narrativa en perpetua formación según el propio trayecto de lectura" (1995, p. 23). Ocasionalmente, ocorre uma certa confusão no conceito de multivocalidade devido à facilidade de elaboração de textos colaborativos no meio digital, podendo ser interpretado também como a possibilidade de co-autoria na redação dos textos. Esse fato não deixa de ser pertinente, talvez por isso, o conceito de multivocalidade pudesse ser compreendido em relação a duas questões: a primeira, no sentido de múltiplas vozes, relativa à construção de uma narrativa literária e a segunda, num sentido mais operacional, relacionada com a cooperação de vários autores para a criação de um mesmo texto ou narrativa. (MIELNICZUK, 2003, p. 100)

Expandindo a definição da autora, consideramos textos colaborativos não apenas aqueles escritos, inicialmente, de forma colaborativa, como o caso da Wikipédia ${ }^{12}$, mas também aqueles que passam por um processo de reconfiguração com a interação dos leitores, que somam novas perspectivas através de comentários, que complementam ou con- 
trapõem o texto original, como, por exemplo, os grupos de discussão, fóruns, comentários ou chats temáticos.

A categoria pessoa é fundamental para o processo enunciativo, pois ela referencia as demais. "Assim, espaço e tempo estão na dependência do eu, que neles se enuncia. O aqui é o espaço do eu e o presente é o tempo em que coincide o momento do evento descrito e o ato de enunciação que o descreve" [grifos do autor] (FIORIN, 2002, p. 41). Para Maingueneau, "o discurso só é discurso enquanto remete a um sujeito, um EU, que se coloca como fonte de referências pessoais, temporais, espaciais" [grifos do autor] (2005, p. 55). Em uma primeira instância de enunciação, temos o enunciador e o enunciatário. Instalados no enunciado, e colocados hierarquicamente em uma posição inferior, temos o narrador, que pode ser implícito ou explícito, e o narratário. Esse narrador pode fazer debreagens entre os atores, um simulacro das suas enunciações. "O discurso reportado é a citação, pelo narrador, do discurso de outrem e não apenas das palavras ou sintagramas. É a inclusão de uma enunciação em outra" (FIORIN, 2002, p. 42). Isso pode ser feito de três formas, com o discurso direto, o discurso indireto e o discurso indireto livre.

O DD dá uma idéia de distanciamento entre o narrador e o personagem e, por conseguinte, de autenticidade, pois reproduz fielmente as palavras do segundo. Maingueneau explica que "o discurso direto (DD) não se contenta em eximir de qualquer responsabilidade, mas ainda simula restituir as falas citadas" [grifos do autor] (2005, p. 140). O autor o caracteriza pelo fato de dissociar claramente duas situações da enunciação: a do discurso citante e discurso citado (MAINGUENEAU, 2005 , p. 140). Fiorin define o Discurso Direto através do mecanismo de debragem,

O discurso direto é um simulacro da enunciação construído por intermédio do discurso do narrador. Como apresenta duas instâncias enunciativas, dois sistemas enunciativos autônomos, cada uma conserva seu eu e tu, suas referências dêiticas, as marcas da subjetividade próprias [grifos do autor] (FIORIN, 2002, p. 72).

No Discurso Indireto (DI), há a apropriação por parte do narrador do discurso da fonte e, a partir de uma análise, ele é reconstruído. Para Maingueneau, "com o discurso indireto, o enunciador citante tem 
uma infinidade de maneiras para traduzir as falas citadas, pois não são palavras exatas que são relatadas, mas, sim o conteúdo do pensamento" [grifos do autor] (2005, p. 149). Desta forma, não há uma debreagem interna no discurso indireto, ou seja, há apenas uma voz, a do enunciador, que é responsável pelo discurso citado e pelo discurso citante (FIORIN, 2002). Já o Discurso Indireto Livre é uma variação do DI; tem a mesma apropriação do discurso do personagem, mas não há uma diferenciação clara entre o que está sendo dito pelo personagem e pelo narrador.

O DIL [Discurso Indireto Livre] é o tipo mais clássico de hibridismo, já repertorizado há muito tempo pelas gramáticas. Cabe-lhe combinar os recursos do DD e DI. [...] A polifonia do DIL não é de duas vozes claramente distintas (DD), nem a absorção de uma voz pela outra (DI), mas a mistura perfeita de duas vozes: em um fragmento no DIL, não se pode dizer exatamente que palavras pertencem ao enunciador e que palavras pertencem o enunciador citante (MAINGUENEAU, 2005, p. 149).

Esse hibridismo é apontado por Fiorin a partir da combinação entre debreagem e embreagem, na qual "o narrador delega a palavra à personagem (debreagem). Em seguida, há uma neutralização entre a primeira e terceira pessoa em proveito da última (embreagem)" (FIORIN, 2002, p. 81).

Entendemos que existe uma forte ligação entre as categorias pessoa e tempo. Para que ocorra uma ação na narrativa é necessário um sujeito e uma ação que estão intrinsecamente conectados. Enquanto a categoria pessoa trata do primeiro, a categoria tempo trata do segundo. Podemos afirmar que esta diz respeito ao momento das ações que se desenvolvem durante a narrativa. Fiorin destaca que esses momentos são definidos a partir de um parâmetro, o agora.

O discurso instaura um agora, momento da enunciação. Em contraposição ao agora, cria-se um então. Esse agora é, pois, o fundamento das oposições temporais da língua. $\mathrm{O}$ tempo presente indica a contemporaneidade entre o evento narrado e o momento da narração. [...] Com efeito, o agora é reinventado a cada vez que o enunciador enuncia, é a cada ato de fala um tempo novo, ainda não vivido (Benveniste, 1974, p. 74). Se o agora é gerado pelo ato de linguagem deslocase ao longo do fio do discurso permanecendo sempre agora. 
Torna-se, portanto, um eixo que ordena a categoria topológica da concomitância vs não concomitância. Esta, por sua vez, articula-se em anterioridade vs posterioridade. Assim, todos os tempos estão intrinsecamente relacionados à enunciação [grifo do autor] (FIORIN, 2002, p. 142).

Ou seja, qualquer mudança de discurso (DD, DI ou DIL) ou qualquer descrição dos personagens vale como link vinculado à dimensão pessoal. Entendemos o processo de deslocamento do agora através do fio do discurso, para criar uma relação temporal entre os episódios, ou blocos de textos associados como dimensão tempo, e que seguem as categorias propostas por Liestøl.

\section{Considerações Finais}

A aplicação do conceito de embreagem e debreagem, dentro das categorias de enunciação - tempo, espaço e pessoa, para a análise de narrativas em estrutura hipertextual pode ser muito profícua, pois permite identificar como a história pode ser contada através de links. Assim é possível identificar a função dos personagens, com uma abordagem voltada para a análise categoria pessoa, ou a dualidade entre descrição observando a questão da passagem de tempo ou a descrição de um espaço. Esse tipo de abordagem já está consolidada em mídia tradicionais em que a transmissão é linear, mas precisa ser revista para um organização textual em rede.

O desenvolvimento de metodologias e estratégias de observação pode ser útil para entender os novos usos das mídias digitais e interativas tanto para o jornalismo quanto para a ficção. Outros elementos como a arquitetura da informação e as interfaces são pontos a serem considerados neste contexto de investigação. Contudo, pretende-se aqui apenas apresentar algumas aproximações teóricas sobre o tema que demanda ainda o desenvolvimento de mais pesquisas para o seu aprofundamento.

\section{Referências}

ARISTÓTELES. Arte Poética. Trad. Paulo Costa Galvão. Rio de Janeiro: Ediouro, s/d. 
CHARAUDEAU, Patrick. Discurso das mídias. São Paulo: Contexto, 2006.

COTTA, Pery. Aristóteles, o pai .genético. do jornalismo. Comum, Rio de Janeiro, v.7, no 19, p. 44-72, ago./dez, 2002.

ECO, Umberto. Lector in Fabula: a cooperação interpretativa nos textos narrativos. 2a Ed. São Paulo: Perspectiva, 2004a.

. Obra Aberta. 9a ed. São Paulo: Perspectiva, 2003.

FABBRI, Paolo. E1 Giro Semiótico. Barcelona: Gedisa, 2000.

FIORIN, José Luiz. As Astúcias da enunciação - As Categorias de Pessoa, Espaço e Tempo. 2a ed. Editora Ática: São Paulo, 2002.

GANCHO, Cândida Vilares. Como analisar narrativas. São Paulo: Ática, 1997.

JOYCE, Michael. Hipertext Narrative. Disponível em: http://noel. pd.org/topos/perforations/perf3/hypertext_narrative.html. Acesso em: 24 jan. 2006.

LAMARCA LAPUENTE, María Jesús. Hipertexto: el nuevo concepto de documento en la cultura de la imagen. (tese de doutorado). Facultad de Ciencias de la Información. Universidad Complutense de Madrid. 2006.

LANDOW, George (org.). Teoría del hipertexto. Barcelona: Paidós, 1997.

LIESTØL, Gunnar. Wittgenstein, Genette y la narrativa del lector en hipertexto. In: LANDOW, George P. (org) Teoria Del hipertexto. Barcelona: Paidós, 1997.

MACHADO, Elias. A Base de Dados como Espaço de Composição Multimídia. In: Suzana Barbosa. (Org.). Jornalismo Digital de Terceira Geração. 1a ed. Covilhã: Labcom Books, 2007, v. 1, p. 102-118.

MACHADO, Elias. A Base de Dados como formato no Jornalismo Digital. In: Antonio Fidalgo; Paulo Serra. (Org.). Actas do VII Lusocom. Covilhã: Universidade Beira Interior, 2005, v. Vol 1, p. 301-310.

MAINGUENEAU, Dominique. Análise de textos de comunicação. 4a ed. São Paulo: Cortez, 2005. 
. Termos-Chave em Análise do Discurso. Belo Horizonte, MG: Ed. UFMG, 2000.

; CHARAUDEAU, Patrick. Dicionário de Análise do Discurso. São Paulo: Contexto, 2004.

MANOVICH, Lev. The language of new media. Boston: MIT Press, 2001.

MIELNICZUK, Luciana. Jornalismo na web: uma contribuição para o estudo do formato da notícia na escrita hipertextual. (Tese de Doutorado) FACOM/UFBA, 2003.

; PALACIOS, Marcos. Considerações para um estudo sobre o formato da notícia na web: o link como elemento paratextual. In: $X$ Compós - Encontro dos cursos de Pós-Graduação em Comunicação, 2001, Brasília, 2001.

MOTTA, Luiz Gonzaga. A Análise Pragmática da Narrativa Jornalística. Trabalhado apresentado no XXVIII Congresso Brasileiro de Ciências da Comunicação. Rio de Janeiro, set 2005.

PALACIOS, Marcos. Hipertexto, Fechamento e o uso do conceito de não-linearidade discursiva. Lugar Comum, Rio de Janeiro, n. 08, p. 111$121,1999$.

. Jornalismo Online, Informação e Memória: Apontamentos para debate. Trabalho apresentado durante as Jornadas de Jornalismo Online, 21 e 22 de junho de 2002, Universidade da Beira Interior, Portugal.

. Natura non facit saltum: Promessas, alcances e limites no desenvolvimento do jornalismo on-line e da hiperficção. e-COMPÓS, Revista eletrônica da COMPÓS, vol. 1, n. 2, Brasília, 2005.

PAUL, Nora; FIEBICH, Christina. The Elements of Digital Storytelling. Disponível em: http://www.inms.umn.edu/elements/index.php, acesso em: 12 de agosto de 2005.

SAN MARTÍN, Patrícia. Hipertexto: Seis propuestas para este milénio. Buenos Aires, La Crujía, 2003.

TRIVINHO, Eugênio. Comunicação, Glocal e Cibercultura: bunkerização da existência no imaginário mediático contemporâneo. Trabalho apresentado no GT de Tecnologias Informacionais de Comunicação e 
Sociedade do XIII Encontro Nacional da COMPÓS, São Bernardo do Campo, SP, junho 2004.

\section{Notas}

[1] No original: Hypertext is, of course, young by almost any measure-- 47 years since Vannevar Bush's Memex, 29 since Engelbart's Augment, 27 since Nelson's hypertext, five years since a number of us gathered for the first of the ACM hypertext meetings in 1987. Narrative is old. [...]This is because hypertext thinks itself to be structural rather than serial thought-- thought in space rather than thought for space (Tradução Nossa).

[2] No original: it should contain both an actor and a narrator; it also should contain three distinct levels consisting of the text, the story, and the fabula; and its "contents" should be "a series of connected events caused or experienced by actors". (Tradução Nossa)

[3] No original: Llamaremos narratividad a todo lo que se presenta cada vez que estamos ante concatenaciones y transformaciones de acciones y pasiones. (...) La narratividad es, radicalmente, un acto configuración del sentido variable de acciones y pasiones; acciones y pasiones que pueden estar organizadas desde al punto de vista de la forma de su contenido, es decir, de su semántica, y pueden ser manifestadas por una forma de expresión distinta (verbal, gestual, musical, etc) (Tradução Nossa)

[4] Para um estudo aprofundado das tipologias de links sugerimos: Levy (1995), Landow (1997), Nielsen e Loranger (2007), Mielniczuk (2003) e Codina (2003).

[5] O autor faz uma diferenciação entre hipertexto e hipermídia considerando a primeira mais relacionada à literatura e a segunda ao audiovisual.

[6] No original: The narrative is constructed by linking elements of this database in a particular order, i.e. designing a trajectory leading from one element to another. On the material level, a narrative is just a set of links; the elements themselves remain stored in the database. [...] An interactive narrative (which can be also called "hypernarrative" in an analogy with hypertext) can then be understood as the sum of multiple trajectories through a database. A traditional linear narrative is one, among many other possible trajectories; i.e. a particular choice made within a hyper-narrative. (Tradução Nossa)

[7] No original: en las teorías de la narrativa, la distinción entre la historia contada y el contar la historia aparece en numerosas constelaciones e contextos. (Tradução Nossa)

[8] As outras categorias de Genette utilizadas são em relação a freqüência e o discurso.

[9] No original: en los hipermedios, la interactividad permite al usuario escoger la velocidad, cantidad y calidad de la información. (Tradução Nossa) 
[10] No original: Instead of narration and description, we may be better off thinking about games in terms of narrative actions and exploration. Rather than being narrated to, the player herself has to perform actions to move narrative forward: talking to other characters she encounters in the game world, picking up objects, fighting the enemies, and so on. If the player does not do anything, the narrative stops. From this perspective, movement through the game world is one of the main narrative actions. (Tradução Nossa)

[11] Wikipédia é uma enciclopédia livre, gratuita e escrita de forma colaborativa. Para visitá-la, acesse http://pt.wikipedia.org

* Marcelo Freire

Doutorando pelo Progra-

ma de Pós-Graduação em

Comunicação e Cultura

Contemporâneas da $\mathrm{Fa}-$ com/UFBA. É professor assistente da Universidade Federal de Santa Maria, campus Frederico Westphalen/RS.

\section{E-mail:}

marcelofreire@gmail.com 